\title{
A dualidade da escola brasileira na primeira metade do século $\mathrm{XX}$ : registros do INEP
}

\author{
The duality of the brazilian school in the first \\ half of the 20th century: records of INEP \\ La dualidad de la escuela brasileña en la primera \\ mitad del siglo $X X$ : registros del INEP
}

ELIANDA FigueIREDO ARANTES TIBALLI ${ }^{1}$

\section{Resumo}

Este artigo tem o objetivo de explicitar as explicações sobre a dualidade da escola brasileira formuladas pelos intelectuais/pesquisadores do Instituto Nacional de Estudos Pedagógicos INEP, na primeira metade do século XX. Com este propósito foram analisados vinte e cinco trabalhos publicados na Revista Brasileira de Estudos Pedagógicos - RBEP, no período de 1944 a 1964, identificados com o descritor qualidade do ensino. Tendo como referência os aportes teóricos e metodológicos formulados por Wolf Lepenies para a história intelectual, foram considerados o contexto histórico, o contexto institucional e o contexto cognitivo do discurso educacional publicado na REBP no período considerado, tornando possível evidenciar que as pesquisas realizadas no INEP na primeira metade do século XX identificaram, na origem da escola pública brasileira e na desigualdade social, a persistência histórica da desigualdade educativa e da dualidade da escola neste país.

Palavras chave: INEP (1944/1964); dualidade da escola, história intelectual

\footnotetext{
${ }^{1}$ Doutora em Educação: História e Filosofia da Educação pela Pontifícia Universidade Católica de São Paulo. Professora Titular do Programa de Pós-Graduação em Educação e da Escola de Formação de Professores e Humanidades da Pontifícia Universidade Católica de Goiás. E-mail: tiballi@terra.com.br
} 


\begin{abstract}
This paper aims at discussing the explanations about the dual education system, formulated by the INEP's intellectuals/ researchers in the early $20^{\text {th }}$ century. For this purpose, twenty-five academic articles, published between 1944 and 1964, in the Brazilian Journal of Pedagogical Studies (Revista Brasileira de Estudos Pedagógicos - RBEP), were analyzed and identified by the keyword 'quality of teaching'. The Wolff Lepenies's theoretical and methodological reference was used for the intellectual history, considering the historical, the institutional and the cognitive contexts of the educational discourse published in the RBEP in this period. The results show that it was possible to identify, in the collected data, the historical persistence of educational inequalities and the dual education system in Brazil since the origin of the Brazilian public school.
\end{abstract}

Keywords: INEP (1944/1964), duality of school, intellectual history

\title{
Resumen
}

El objetivo de este artículo es explicitar las explicaciones sobre la dualidad de la escuela brasileña formuladas por los intelectuales/investigadores del INEP en la primera mitad del siglo XX. Con este propósito, veinticinco trabajos publicados en la Revista de Estudios Pedagógicos - RBEP, en el periodo de 1944 a 1964, fueron analizados e identificados con la palabra clave 'calidad de la enseñanza'. Los aportes teóricos y metodológicos formulados por Wolff Lepenies fueron utilizados como referencia para la historia intelectual, considerando los contextos histórico, institucional y cognitivo del discurso educacional publicado en la RBEP en este periodo. Fue posible evidenciar en las investigaciones realizadas en el INEP, en la primera mitad del siglo XX, la persistencia histórica de la desigualdad educativa y la dualidad de la escuela en Brasil desde el origen de la escuela pública brasileña.

Palabras clave: INEP (1944/1964); dualidad de la escola, historia intelectual. 
É usual na historiografia brasileira considerar a década de 1930 como marco cronológico do avanço do processo de industrialização no país e da entrada do Estado na definição de políticas sociais, entre elas a criação do sistema público de ensino. Contudo, foi na década de 1950 que esse processo se intensificou, exigindo um aprofundamento da ação do Estado nas políticas públicas para a reordenação da sociedade, sendo a educação fator preponderante nesse processo. De um lado, o desenvolvimento capitalista engendrou a necessidade de fornecer conhecimentos a camadas cada vez mais numerosas, seja pelas exigências próprias da produção, seja pelas necessidades de consumo que essa produção acarretava. De outro lado, o desenvolvimento industrial dos anos de 1950, concomitantemente com um profundo processo inflacionário, desencadeou a elevação do peso do operariado fabril, não apenas pelo seu aumento numérico, mas principalmente pela pressão cada vez mais acentuada que essa parcela da população, ao lado do setor médio, também descontente, exerceu no sentido de obter melhorias de suas condições de vida. Essas pressões foram fundamentais para que se ampliassem as áreas de atividades do Estado, tornando necessária a ampliação do sistema público de ensino.

No Brasil, até a Proclamação da República, a taxa de analfabetismo atingia 9\% da população de mais de quinze anos de idade. Na década de 1930, essa taxa caiu para $75 \%$. É, contudo, na década de 1950 que a implantação da rede pública de ensino efetivou-se, conforme demonstram as estatísticas que apontam uma taxa de analfabetismo igual a $51 \%$ para o período. Essa diminuição da taxa de analfabetismo correspondeu ao aumento numérico da oferta de escolarização registrado no mesmo período.

A ampliação do acesso aos estudos, iniciada nas primeiras décadas do século XX, com a estruturação da rede pública de ensino em vários Estados brasileiros, multiplicou-se, impondo uma nova perspectiva de análise da problemática educacional. À disparidade de acesso juntaram-se as desigualdades no próprio desempenho escolar fazendo emergir uma série de estudos e pesquisas voltados para a qualidade e para o rendimento do ensino público. Ao mesmo tempo, o contexto de urbanização, industrialização e estruturação da rede nacional de educação pública exigia novos aportes explicativos das contradições que engendrava e impunha a racionalização do sistema escolar de modo a adequá-lo às novas exigências sociais, econômicas e culturais do país. Racionalizar implicava diagnosticar e planejar as ações educativas imprimindo-lhes o rigor da cientificidade.

Estudos sociológicos da educação foram incorporados pelo pensamento educacional brasileiro no período e a desigualdade educativa, antes considerada prioritariamente como problema psicopedagógico, passa a ser considerada também como problema social, explicitado pelos intelectuais que difundiram o modo sociológico de pensar a educação no país. A desigualdade educativa ou de acesso à educação assumiu posição central na pesquisa sociológica e, a exemplo do que vinha ocorrendo nos Estados Unidos, Inglaterra e França, os inquéritos estatísticos censitários, e posteriormente os surveys, tornaram-se frequentes, revelando não apenas aquelas desigualdades, mas evidenciando outros problemas que, no conjunto, resultaram no que se convencionou chamar dualidade da escola brasileira. 
Várias dessas investigações foram realizadas pelos pesquisadores que atuavam no Instituto Nacional de Estudos Pedagógicos - INEP e estes não apenas consideravam a educação escolar como objeto, como também tornaram aquele Instituto, desde a sua criação, um locus privilegiado para realização de pesquisas sobre a realidade educacional brasileira $^{2}$ Explicitar as explicações da dualidade da escola brasileira, formuladas pelos pesquisadores do INEP na primeira metade do século XX, é o propósito deste artigo.

Esse propósito permitiu circunscrever a pesquisa que deu origem a este artigo a 25 trabalhos identificados com o descritor 'qualidade do ensino', publicados na Revista Brasileira de Estudos Pedagógicos nas décadas de 1944 a 1964. A data inicial corresponde à primeira edição da RBEP e a data final ao período das mudanças estruturais ocorridas INEP e que interromperam as pesquisas que vinham sendo ali realizadas.

A análise de conteúdo foi utilizada como procedimento metodológico para a seleção e sistematização dos dados. Nesse procedimento, as operações de análise e sistematização são consideradas como recursos auxiliares para identificação dos dados que devem ser apreendidos no curso de sua constituição histórica, para se chegar à sua síntese interpretativa, o que requer uma análise de conjunto das informações extraídas das fontes e não o cotejamento dos dados particulares nelas obtidos. Essa atitude metodológica exigiu uma abordagem histórica, o que implicou em evitar os simplismos dos enquadramentos genéricos e a diluição das evidências em conceitos formulados a priori. Este entendimento, que tem os aportes teóricos e metodológicos formulados por Lepenies (1984) no âmbito da história intelectual ${ }^{3}$ como principal referência, tornou necessário considerar para a produção deste trabalho: (1) o contexto histórico como fonte para a apreensão dos nexos explicativos da expansão da escola pública brasileira no período considerado; (2) o contexto institucional para identificação do lugar institucional de onde foram formuladas as primeiras explicações sobre a dualidade da escola; (3) o contexto intelectual que instigou os estudos investigativos que resultaram nas explicações formuladas pelos pesquisadores do INEP para a dualidade da escola brasileira.

\section{A expansão da escola pública sob o crivo da história}

O ensino fundamental, vinculado ao sistema de educação coordenado pelo governo central e destinado à educação popular, somente teve início, no Brasil, a partir do século XX, expressando-se de forma oficial com a criação do Ministério da Educação e Saúde (1930) e com a ampliação da oferta de vagas colocados à disposição da população. A oferta de escolarização, que até o início do século XX tinha sido prioritariamente dirigida à

\footnotetext{
${ }^{2}$ Estudos como o de Brandão (1995,1999); Nagle (1974), Mendonça (1997, 2001, 2005, 2006); Gandini (1995); Schwartzman et alii (1984), Gouveia (1971, 1985), Warde (2000); Cunha (2004, 1999, 1994, 2011), Vidal (2013), Xavier ( 2004, 2006), entre outros, representam o esforço já empreendido pelos pesquisadores que se dispuseram à investigação esse tema.

${ }^{3}$ Neste artigo, história intelectual tem o significado explicitado por Vieira: “A história intelectual investe na análise dos processos de produção, circulação e recepção das ideias e dos discursos científicos, políticos, pedagógicos ou artísticos, desenclausurando-os da lógica e do método internalista da tradicional história das ideias. Reassociar as ideias, os sentidos, as representações e/ou os discursos aos seus contextos de produção e de recepção é condição para construir uma história intelectual intimamente articulada à história das linguagens, das profissões ligadas à esfera cultural, das formas de transmissão da cultura e dos meios e dos lugares de difusão do conhecimento". (Vieira, 2008, p.80).
} 
elite da sociedade composta pelo patriarcado rural, passa a atender também às demandas do operariado emergente, que buscava na escola a chance de ascensão social.

De fato, o ensino público expandiu-se consideravelmente a partir dos anos 1930, embora as alterações numéricas indicadoras da ampliação da rede escolar não tenham eliminado a insuficiência de escolas, conforme denúncia de Freitas:

É inacreditável a incapacidade social e pedagógica da escola brasileira [...]. Se não fora a alfabetização do ensino supletivo, combinada com a instrução que o lar - realizando, aliás, notável obra educativa - ainda proporciona em larga escala às crianças brasileiras; se, por conseguinte tivesse o Brasil o preparo das suas novas gerações confiado exclusivamente à escola fundamental comum que os seus governos lhe conseguiram dar, encontrar-se-ia ele neste momento em regressão cultural, mantendo-se francamente ascensional a sua curva de analfabetos - tanto a absoluta como a relativa. Tal acontecendo - ainda que pareça paradoxo - não por falta de escola, mas por falta de ensino, pois nossas escolas deixam-se esvaziar de alunos, esvaziando-se, por conseguinte, de seu verdadeiro sentido social. (FREITAS, 1940, p.20-24).

Se, por um lado, permanecia a insuficiência de escolas e um significativo índice de analfabetismo no Brasil, por outro, a expansão do ensino público era um fato incontestável $^{4} \mathrm{e}$, concomitantemente com a expansão da produção industrial e com o aumento da população urbana, compunha o conjunto das transformações desencadeadas pela sociedade brasileira na primeira metade do século XX.

É preciso realçar, entretanto, que, embora a expansão do ensino público no Brasil tenha se realizado de forma concomitante com o avanço da industrialização, não há ainda estudos conclusivos que demonstrem a relação entre um e outro daqueles processos. As evidências demonstram que a arrancada da economia industrial fez emergir uma população urbana que criou uma demanda efetiva por oferta de escolas a partir dos anos de 1930. O capitalismo industrial, impulsionado pela Revolução de 1930, acarretou o rompimento da velha ordem oligárquica e trouxe para a pauta das reivindicações dos estratos sociais emergente, a necessidade crescente de educação escolar, sustentada pela ideologia liberal da igualdade de oportunidades, que colocava a escola como via de ascensão social. Essa demanda foi eminentemente quantitativa pois, considerando que os padrões de educação das elites eram os que interessavam aos setores sociais emergentes, o crescimento da demanda social de educação determinou a expansão de uma escola que continuou a estruturara-se segundo o modelo vigente, ou seja, a escola acadêmica cujas raízes encontravam-se na pedagogia jesuítica.

\footnotetext{
${ }^{4}$ Em 1932 haviam 27.662 escolas primárias no Brasil, em 1942 esse número subiu para 43.975 (Serviço de Estatística e Saúde. In: RBEP. Vol.2, n.4, p.96, 1944).
} 
Vários outros fatores são conjugados na estruturação do sistema público de ensino de uma dada sociedade, sendo a herança cultural, a ordem política e o sistema econômico os que influenciam mais diretamente na definição do tipo de ensino solicitado pelos diferentes estratos sociais e na definição do tipo de ensino que lhes é oferecido. A tendência comumente registrada pela história da educação é aquela em que a instauração dos Estados nacionais, o desenvolvimento industrial e o crescimento dos centros urbanos fazem emergir a oferta de escolas para atender à necessidade de preservação da unidade nacional e de ampliação da população escolarizada, requisitada pela indústria e pelo setor de serviços. Considerada essa tendência, tem-se por suposto que a estruturação do sistema de ensino e o aumento do índice de alfabetismo são decorrentes diretos do avanço do processo de industrialização.

Alguns estudos já apontaram que esta sequência nem sempre tem comprovação histórica. Fatores como a industrialização e a urbanização não podem ser responsabilizados, com exclusividade, pela ampliação da oferta de escolas e pelo aumento do índice de alfabetismo. Os dados apresentados por Petitat (1994, p.15-151), referentes a alguns países europeus, são confirmadores dessa hipótese. A Suécia, por exemplo, em 1850 , era um país com $10 \%$ da população vivendo em centros urbanos, $35 \%$ absorvidos pelas atividades industriais ou pela prestação de serviços e uma taxa de $10 \%$ de analfabetismo. Em posição oposta estava a população do Inglaterra e do País de Gales, em 1985 , com $84 \%$ da população em atividades industriais ou de prestação de serviços, $50 \%$ da população urbanizada e uma taxa de $30 \%$ a $35 \%$ de analfabetismo.

No Brasil, entre 1900 e 1920, a renda per capita cresceu 63,35\%, a população urbana aumentou em 60\%, enquanto o índice de alfabetismo apresentava uma elevação de 7\%. De 1920 a 1940, período de intensificação do processo de industrialização, a renda per capita e a população urbana cresceram em torno de $100 \%$ e o alfabetismo aumentou apenas $24,4 \%$.

Assim, diante desses dados que colocam em dúvida a explicação que estabelece uma relação linear entre alfabetismo e industrialização, outros fatores precisam ser considerados nos estudos sobre estruturação e expansão dos sistemas públicos de ensino. Petitat (1994) considera a mobilidade geográfica e social - favorecidas pela industrialização, pela ação do Estado e da Igreja, quando em concorrência pela instrução popular - além do sufrágio universal, do serviço militar obrigatório e da influência reivindicativa da classe operária, fatores que concorrem para a estruturação e ampliação dos sistemas nacionais de ensino. Há, contudo, uma combinação diferenciada desses fatores na definição da defasagem da alfabetismo em cada sociedade. O comum em todas elas, ainda segundo o autor, é que:

Logo que a escrita tornou-se bastante disseminada, o analfabeto passou a ser visto como indigno, e esta desvalorização social estimulou os pais a colocar os filhos na escola, pelo menos por alguns anos. Trata-se de um sinal indiscutível de ascendência da cultura da escrita sobre a cultura oral, então em vias de inferiorizarão. (PETITAT, 1994, p. 152). 
No Brasil, embora se evidencie que os fatores apontados por Petitat tenham contribuído para a expansão do ensino público, a reivindicação da classe média emergente parece ter sido a influência mais determinante. Apesar da dificuldade de avaliar esta hipótese, é certo que, nesse país, a demanda antecipou a oferta por duas razões básicas: a herança cultural e a estratificação social. A demanda não viria da zona rural cuja economia de base agropastoril, de método rudimentar e em regime de subemprego não sentia nem expressava qualquer defasagem de escolarização. Não viria também da elite oligárquica, já atendida em suas necessidades imediatas pelas escolas a ela destinadas e com possibilidades financeiras para custear os estudos mais avançados de seus descendentes em qualquer outro país. A reivindicação por escolas públicas viria da classe intermediária, que se iniciara com a mineração e se tornara um estrato social significativo com o avanço da industrialização. Nos estudos de Lourenço Filho sobre a evolução da educação escolar no Brasil, encontra-se um argumento elucidativo dessa explicação.

Onde haja grupos mais adensados, com economia de mercado ascendente e maior diferenciação do trabalho, por deslocamento crescente de elementos ativos dos setores econômicos primários (agricultura, pecuária, mineração) para as manufaturas e atividades industriais em geral, quando isso se passa, vêm crescer as ocupações terciárias (administração, transporte e serviços em geral) cuja influência na integração das pequenas comunidades logo se faz sentir. Então a leitura e a escrita passam a ter preço, são sentidas como úteis e benéficas, e a demanda de ensino normalmente se eleva, ao mesmo tempo que maiores recursos, advindos de maior produção, possibilitam maior e mais diferenciada oferta. (LOURENOÇO FILHO, 1965, p.266).

Nessa análise da implantação e expansão do ensino público brasileiro, evidencia-se dois fatores que influenciaram decisivamente na definição do tipo de ensino fundamental que seria implantado no país. O primeiro foi a demanda por escolarização que, vinda dos estratos sociais emergentes e concentrados nos centros urbanos no início do século XX, se fez orientada pelo princípio vigente nas sociedades escravocratas, segundo o qual o título acadêmico era garantia de trabalho intelectual, posição de comando e distintivo de classe, em oposição ao trabalho prático, executado sempre pelas classes subalternas. $\mathrm{O}$ segundo foi o caráter do aumento das escolas públicas de ensino fundamental, que se deu sobretudo em decorrência da demanda social por escolarização e não apenas pela oferta de oportunidade exigida pelo avanço tecnológico da sociedade. Esse fato determinou a expansão do ensino público sem a devida alteração de sua estrutura tradicional, mantendose a organização livresca de antes, que tornava a escola pública brasileira obsoleta do ponto de vista pedagógico, inadequada para a escolarização dos estratos da população que a ela chegavam. 
Não obstante, essa escola foi reconhecida como inadequada somente quando o movimento de modernização e redefinição político-econômica da sociedade brasileira abalou o tradicional poder político das oligarquias rurais, momento em que havia um campo fértil para sua crítica entre os profissionais da educação que desencadearam o movimento de renovação do ensino no Brasil.

\section{A qualidade do ensino sob a 'aritmética política' do INEP}

Embora o discurso pedagógico tenha registrado o debate em trono da difusão do ensino e da renovação da escola, e alguns Estados tenham se adiantado na implantação de projetos e reformas educacionais orientadas pelos princípios escolanovistas - São Paulo (1920 e 1930); Ceará (1923); Rio Grande do Norte (1925 e 1928); Distrito Federal (1928); Paraná (1927 e 1928); Pernambuco (1929); Bahia (1929); Minas Gerais (1927) - essas tentativas não conseguiram consolidar um sistema nacional de ensino. Para F. Azevedo (1958, p. 43), “ do ponto de vista cultural e pedagógico a República foi uma revolução que abortou", por não ter tido a decisão de implantar, o novo regime, uma transformação radical no sistema de ensino, capaz de provocar uma revolução cultural das elites intelectuais e políticas, que ele considerava como condição necessária para a implantação de novas instituições democráticas. Os ideais educacionais difundidos pelo movimento político-social do início do século XX conseguiram, contudo, atribuir uma importância cada vez maior ao tema da escolarização da população e à profissionalização do campo educacional.

Até aquele momento, a escolarização era tratada por homens públicos e por intelectuais que eram 'educadores', num tempo em que os assuntos educacionais não constituíam, ainda, uma atividade suficientemente profissionalizada. Apenas na década final da Primeira República a situação vai ser alterada, com o aparecimento do 'técnico' em escolarização, a nova categoria profissional; este é que vai daí por diante tratar, com quase exclusividade, dos assuntos educacionais. (NAGLE, 1974, p. 101-102).

No campo educacional, os educadores profissionais vinham sendo convocados pela elite burocrática desde os anos de 1920, em virtude da competência e do saber de que dispunham em suas respectivas áreas de atuação. Embora as relações de poder continuassem exercendo influência no recrutamento para os cargos de prestígio nos órgãos do Estado, o mérito pessoal reclamado pelo princípio da racionalidade tronou-se também um critério de contratação. A geração de intelectuais recrutada pelo governo nas primeiras décadas do século XX conseguiu prestígio junto à sociedade brasileira, ampliou os espaços de atuação na segunda República e implantou o critério técnico nas decisões das questões educacionais. 
No que diz respeito às relações entre os intelectuais e o Estado, o regime Vargas se diferencia sobretudo porque define e constitui o domínio da cultura como um 'negócio oficial', implicando em orçamento próprio, a criação de uma 'intelligentzia' e a intervenção em todos os setores da produção, difusão e conservação do trabalho intelectual e artístico. (MICELI, 1979, p.131).

A influência desses profissionais da educação se concretizou principalmente no IV Conferência de Nacional de Educação- CBE realizada pela Associação Brasileira de Educação - ABE, em 1931, ocasião em que o Ministro da Educação Francisco Campos, solicitou aos educadores ali reunidos, que definissem o sistema pedagógico da Revolução. O atendimento a essa solicitação foi subscrito como "Manifesto dos Pioneiros “, lançado em 1932.

Nesse mesmo sentido agiu o Ministro Capanema que, tendo assumido o Ministério da Educação e Saúde em 1934, convocou seus contemporâneos, membros da mesma geração dos intelectuais modernistas e renovadores, para composição do quadro de profissionais do Ministério. Em 1938 foi criado o Instituto Nacional de Estudos Pedagógicos-INEP, e para sua direção foi designado Manoel Bergstrom Lourenço Filho.

Embora os objetivos e as atividades iniciais do INEP estivessem concentrados nas atividades de avaliação psicológica de candidatos do serviço público e na padronização de teste de escolaridade, os trabalhos relacionados com os inquéritos escolares foram os que mais contribuíram para as realizações posteriores daquele instituto. O Censo de 1920 havia fornecido dados alarmantes sobre os índices de analfabetismo entre a população brasileira - 64,94\% da população acima de 15 anos eram analfabetos - conhecer a evolução desse quadro se colocava, portanto, como prioritário para a previsão e o controle dos projetos educacionais por parte daqueles que administravam o ensino público no país.

A não realização do censo de 1930 deixou à mercê das possibilidades os números relativos ao movimento escolar. Embora alguns Estados promovessem levantamentos estatísticos próprios, a ausência de critérios comuns para a coleta dos dados dificultava a síntese estatística e a formulação de um quadro geral da situação educacional brasileira. Em 1931, por sugestão dos educadores reunidos na IV CBE, foi firmado o Convênio Interestadual de Estatísticas Educacionais, com o objetivo de sistematizar e padronizar os critérios de coleta de dados sobre o ensino, a ser realizada anualmente sob a responsabilidade do órgão competente do Estado.

A ordenação desses dados ficava sob a responsabilidade do Serviço de Estatística da Educação e Saúde -SEES, órgão técnico subordinado administrativamente ao Ministério da Educação e Saúde - MES e, ao mesmo tempo, um dos órgãos centrais do Instituto Brasileiro de Geografia e Estatística - IBGE. Esses dados, publicados anualmente pela SEES, a partir de 1932, em boletins e revistas especializadas ${ }^{5}$, possibilitaram o conhecimento do sistema de ensino, tendo sido o INEP o órgão que mais diretamente se

\footnotetext{
${ }^{5}$ Entre essas publicações, as que divulgavam dados estatísticos mais completos sobre o ensino brasileiro, estão a Revista Brasileira de Estatística, o Anuário Estatístico do Brasil e a séria $O$ Ensino no Brasil, editados sob a responsabilidade da SEES-MES-IBGE.
} 
apropriou dos benefícios daquelas informações, conforme atesta o Relatório Estudos e Pesquisas Educacionais no Ministério da Educação e Cultura, no item em que apresenta os antecedentes históricos do INEP.

No que diz respeito à compreensão mais ampla dos fatores educacionais brasileiros valeu-se o INEP sobretudo dos dados estatísticos colhidos pelo SEES (Serviço Estatística da Educação e Saúde) para com eles caracterizar o aspecto quantitativo da educação no Brasil, salientando as deficiências numéricas e o ritmo de desenvolvimento. Por outro lado, levantou a organização dos sistemas administrativos da educação em todos os Estados, publicando uma séria de folhetos a esse respeito. (INEP EDUCAÇÃO E CIÊNCIAS SOCIAIS, n.1, p.12-13, 1956).

Sob a influência dessa 'aritmética política', , as atividades desenvolvidas pelo INEP durante a gestão de Lourenço Filho foram orientadas pelos princípios da racionalidade técnica. Em decorrência dessa orientação os dados estatísticos sobre o ensino brasileiro receberam, naquele instituto, o tratamento estatístico que possibilitou o conhecimento da realidade do ensino no país. Os dados demonstravam a insuficiência de escola para o atendimento da população em idade escolar, o baixo rendimento do sistema de ensino em número de aprovação e conclusão de curso e, em decorrência disso, o elevado índice de analfabetismo.

Assumindo a direção do INEP no início de 1964, Murilo Braga encontrou as áreas de carência escolar já diagnosticadas e recebeu a responsabilidade de administrara os recursos do Fundo Nacional de Ensino Primário, em decorrência da extinção da Diretoria do Ensino Primário e Normal, cujas atribuições foram transferidas para o INEP. Com tais condições, os trabalhos realizados nos seis anos de gestão de Murilo Braga estiveram concentrados na expansão da rede escolar primária e normal e nos cursos de aperfeiçoamento de professores primários. De fato, sua gestão promoveu o aumento da matrícula escolar, mas os levantamentos estatísticos demonstraram que permanecia a insuficiência de escolas e, mais que isso, demonstraram o baixo rendimento do ensino público, já que apenas aproximadamente $8 \%$ dos alunos matriculados no ensino primário conseguiam chegar à $4^{\mathrm{a}}$ série, durante o período de 1944 e 1953.

Esses dados sobre a escola pública, revelados anualmente, foram analisados pelo discurso pedagógico como uma "crise do ensino", e divulgados em vários artigos publicados em jornais e revistas do início dos anos de 1950. A RBEP publicou alguns desses artigos que, no conjunto, apresentavam uma crítica à dualidade do sistema de ensino, considerando-a com fator responsável pelo baixo índice de escolaridade da população, e pelo caráter seletivo da escola brasileira.

\footnotetext{
${ }^{6}$ Aritmética política, segundo Forquin, são estudos com “predileção pelas grandes enquetes sociais e pela coleta de dados descritivos, uma certa desconfiança em relação às grandes construções teóricas e uma preocupação constante por uma inserção social e política numa ótica reformadora. (FORQUIN, 1993, p.70).
} 
A primeira referência à "crise do ensino" publicada pela RBEP, foi o artigo de Abdgar Renault em 1953. Lourenço filho e Anísio Teixeira figuram entre os que mais publicaram artigos sobre o assunto, tendo este último apresentado uma síntese de suas considerações a respeito da crise do ensino em seu livro Educação não é privilégio, publicado em 1957. A expansão acelerada do número de matrículas, a insuficiência de escolas, o baixo rendimento escolar e a dualidade do ensino foram os argumentos utilizados para comprovar a crise na educação brasileira. O pressuposto dessa crítica vinha do ideal da igualdade de oportunidades para o qual a função social da escola seria de possibilitar a todos o acesso aos bens culturais transmitidos para a garantia da unidade coletiva. A esse pressuposto Anísio Teixeira acrescentava a compreensão pragmática e explicava que todo o século XIX foi uma luta pela realização plena dos ideais escolares da democracia.

Só muito lentamente é que a escola comum se emancipou dos modelos intelectualistas para dar lugar à escola moderna, prática e eficiente, com um programa de atividades e não de 'matérias', iniciadoras nas artes do trabalho e do pensamento reflexivo, ensinando o aluno a viver inteligentemente e a participar responsavelmente de sua sociedade. (TEIXEIRA, 1956, p. 4).

Até meados do século XX, o aumento acelerado do número de escolas, afirmavam seus críticos, se fez sem a devida adequação de seus propósitos e de seus currículos às exigências da sociedade moderna. A escola brasileira continuava acadêmica e dualista. Para Teixeira nossas escolas " arcaicas em seus métodos e seletivas nos currículos, não são técnico-profissionais, nem são de cultura geral, seja lá em que sentido tomarmos o termo" (1956, p.11). De inspiração francesa, o ensino no Brasil era dividido entre escola primária, primária complementar, escola normal e as profissionais - comércio e agricultura - que constituíam a rede pública de ensino, e o ginásio e a academia que eram frequentados por alunos oriundos das classes socialmente privilegiadas.

Essa escola foi acusada de seletiva por classificar os alunos não segundo suas aptidões, mas de acordo com sua origem social. Porque acadêmica e não profissionalizante a escola não conseguia formar a todos, principalmente depois que passou a receber um maior número de crianças das camadas populares da sociedade. Os altos índices de analfabetismo, ao lado da pequena porcentagem da população em idade escolar efetivamente matriculada na escola e do número insignificante de alunos ingressos que concluíam o curso primário e prosseguiam seus estudos no ensino médio, comprovam o caráter seletivo e classificatório da escola. Em suas críticas dirigidas a essa escola Renault afirmava:

A crise educacional brasileira, é assim, um aspecto da crise brasileira de readaptação institucional. A escola transplantada para o nosso meio sofreu deformações que a desfiguram e a levam assumir funções não previstas nas leis que buscam disciplinar, impondo-se nos um exame de situação à luz dessa realidade e não das aparências legais, para descobrirmos as causas e os remédios de sua crise. (RENAULT, 1953, p.27). 
Tratava-se de uma crítica ao sistema de ensino vigente no Brasil, em que prevalecia uma escola propedêutica e seletiva, que ignorava os preceitos escolanovistas da educação para o trabalho e se fazia em desacordo com a racionalidade científica, o fundamento do discurso pedagógico da época moderna.

\section{A dualidade da escola sob o crivo do ideal de escola e de democracia}

Atento às essas denúncias e ciente dos problemas da educação brasileira que vinha ajudando a elucidar, Anísio Teixeira, que assumiu o INEP entre 1952 e 1964, imprimiu uma nova orientação administrativa e pedagógica ao Instituto. Ciência e democracia foram os princípios básicos a partir dos quais construiu seu ideário pedagógico, que tinha por propósito a constituição de uma sociedade democrática. Anísio Teixeira via a democracia como um programa de ação a ser intencionalmente perseguido por meio da educação.

O ideal, a aspiração da democracia pressupõe um postulado fundamental ou básico, que liga indissoluvelmente educação e democracia. Esse postulado é o de que todos os homens são suficientemente educáveis para conduzir a vida em sociedade, de forma a cada um e a todos dela partilharem como iguais, a despeito das diferenças das respectivas histórias pessoais, e das diferenças propriamente individuais; [...] ou a educação se faz processo de modificações necessárias na formação do homem para que se opere a democracia, ou o modo democrático de viver não poderá efetivar. (TEIXEIRA, 1957, p.205-206).

A escola básica de ensino fundamental, na compreensão de Teixeira, expressão máxima de um ensino democrático, deveria ser estendida a todos e ter por objetivo formar o 'trabalhador comum'. Não deveria ter, portanto, o caráter propedêutico que sempre orientou o ensino fundamental no país, e sim " dar ao brasileiro o mínimo fundamental de educação [...], uma educação de base, capaz de habilitar o homem ao trabalho em suas formas mais comuns" (TEIXEIRA, 1957, p. 49). Deveria, ainda, ser descentralizada, regionalizada e identificada com os costumes de cada região. Portanto, comum não pela uniformidade, mas pela equivalência cultural. Para Anísio Teixeira era inevitável a diferenciação do ensino entre as várias regiões do país, na medida em que entendia a educação como processo de adaptação do homem ao seu meio. A equivalência residiria, então, nos objetivos propostos para cada grau de ensino e não na uniformidade de seus conteúdos.

Anísio Teixeira considerou que o advento da civilização industrial e democrática, tornou indispensável a generalização da leitura e da escrita como forma de melhoria das condições de vida e de acesso ao trabalho. Desse modo, os índices de alfabetismo tornaramse expressões do estado de progresso de um povo. No Brasil, este fato provocou uma inversão: aumentar o índice de alfabetização passou a ser visto como condição para se tornar 
um povo civilizado. "A inversão está em que a educação é um fenômeno da civilização e mudar a educação implica mudar também a civilização." (TEIXEIRA, 1953, p.19). Essa inversão provocou a expansão desenfreada do sistema do ensino, desconsiderando-se a necessária transformação da sociedade brasileira, de modo que esta pudesse atender às novas exigências sociais, técnicas e científicas. Essa escola, assim ampliada, além de não conseguir manter os alunos durante os anos necessários para a conclusão do ciclo da educação básica, desenvolveu uma cultura tendencialmente acadêmica obsoleta, reduzindo seu papel à "seleção da elite semiletrada e parasitária". (Idem).

A demanda pela escolarização, em vista da expansão das escolas públicas, que vinha sendo efetivamente concretizada, foi contida no interior da própria rede de ensino. Medidas tradicionais adotadas terminaram promovendo altíssimas taxas de evasão e repetência garantindo a seletividade promovida no interior da escola. Esta seletividade era escamoteada pela expansão da rede de ensino, mas efetivada por medidas que garantiam a dualidade seletiva da escola: "um mínimo reduzido, acadêmico, destinado a formação da elite e outro primário, seguido de escolas normais e profissionais destinadas ao povo". (TEIXEIRA, 1956, p.272). Assim organizada a escola, garantia-se a descontinuidade da formação acadêmica entre os diferentes níveis e, para a classe trabalhadora, a perpetuação de um ensino arcaico, propedêutico, desvinculado das funções profissionais do trabalho e ditada pelas novas exigências do mercado de trabalho, impostas pelo acelerado avanço do capital na sociedade moderna. Cioso das necessidades de 'reconstrução' da escola pública, já em seu discurso de posse no INEP deixava registrado com que propósito assumia o cargo:

Cumprir-nos-á, assim e para tanto, medir o sistema educacional em suas dimensões mais íntimas, revelando ao país não apenas a quantidade das escolas, mas a sua qualidade, o tipo de ensino que ministram, os resultados a que chegam no nível primário, no secundário e no superior. Nenhum progresso, principalmente qualitativo, se poderá conseguir e assegurar, sem primeiro, saber-se o que estamos fazendo. [...] se conseguirmos, porém, estudos objetivos que aqui sugerimos, e sobre eles fundamos diagnósticos válidos e aceitos, não será difícil a elaboração de métodos de tratamento e a indicação dos prognósticos. (TEIXEIRA, 1952, p.78).

Com esse discurso estavam lançadas as bases da administração que Anísio Teixeira imprimiu no INEP, cujo princípio orientador era o entendimento de que a escola estava sujeita a três dimensões básicas: normatizações administrativas externas, organização técnico-pedagógica interna e conjunto de forças sociais que influenciavam e que poderiam receber influência da escola. Nesta perspectiva, administrar o sistema público de ensino supunha análise da influência do meio sobre a escola e da escola sobre o meio, o que resultaria no diagnóstico e na explicação da situação escolar e no planejamento de sua reconstrução. (TEIXEIRA,1956, p. 20). 
Não obstante o empenho de Anísio Teixeira e de muitos outros intelectuais partícipes do movimento de renovação da escola brasileira nos primeiros decênios do século XX, a expansão do ensino não se isentou dos conflitos decorrentes das relações sociais e se estruturou em bases hierarquizadas que tornaram desiguais o acesso ao conhecimento e diferenciaram a organização e o funcionamento das instituições escolares.

A ampliação da rede escolar, que por meio da multiplicação de vagas nas escolas públicas colocava para o Estado problemas de ordem administrativa e pedagógica, passou a exigir do poder público maior conhecimento da população escolar e do funcionamento das instituições escolares. A nova situação do país configurava um novo debate e um novo ideário educacional: a democratização das oportunidades escolares. (NOGUEIRA, 1990, p. 90). Nesse contexto inaugura-se no Brasil um modo sociológico de pensar a educação.

O quadro geral de mudanças educacionais do pós-guerra, provocou o aparecimento de toda uma corrente de pesquisa educacional nesse momento "invadida pelos cientistas sociais" - que Karabel e Halsey (1977) chamaram de empirismo metodológico por tratar-se de investigações empíricas - frequentemente quantitativas - cujo esmero metodológico quase sempre conotou rigor, à época. As preferências, quanto ao objeto da pesquisa, recaíam - como bem convinha à época - sobre as desigualdades educacionais e sobre a problemática da democratização do ensino. Calculava-se assim as taxas de escolarização segundo as categorias socioeconômicas: estabelecia-se correlações entre o desempenho escolar e uma séria de fatores sociais tais como: idade, sexo, habitat, profissão e nível escolar dos pais, tamanho das famílias, etc. (NOGUEIRA, 1990, p. 54-55).

Seja o "empirismo metodológico", seja a "aritmética política " anteriormente citados, importa evidenciar a orientação metodológica que modificava substancialmente a pesquisa educacional e que no Brasil consubstanciou-se na passagem da fase ensaísta, centrada na explicação lógica dos fatos educacionais, para a pesquisa empírica e sistemática dos fenômenos educacionais.

Estas escolhas metodológicas, como qualquer outra, não estiveram isentas de propósitos prévios e, nesse sentido, aquelas investigações traziam embutido um modo específico de explicar a realidade. No caso das pesquisas educacionais realizadas pelo INEP nos anos de 1950 e 1960, a ênfase posta nos procedimentos metodológicos como garantia de cientificidade do trabalho investigativo resultou em trabalhos monográficos, com descrição pormenorizada dos dados apanhados in loco, ou seja, circunscritos à descrição empírica do setor delimitado como objeto de estudo.

Esses estudos foram constituidores de um mapeamento exaustivo da educação escolar no Brasil daquele período e nisso trouxeram uma contribuição de fundamental importância. Em nome da democratização do ensino e da igualdade de oportunidades 
educacionais, descreveram a realidade educacional ressaltando seus problemas, evidenciando que a expansão do ensino no Brasil não esteve isenta dos conflitos que gestaram a dualidade da escola brasileira. Os estudos realizados pelo INEP revelaram mais especificamente que, desde sua origem, a escola brasileira reflete a desigualdade social ao promover a desigualdade educativa e, ancorada na dualidade que destina de modo diferenciado as suas finalidades, atende aos alunos de modo também diferenciado, conforme suas origens de classe.

\section{Considerações Finais}

As pesquisas realizadas no INEP nas primeiras décadas do século $\mathrm{XX}$ revelavam a desigualdade educacional no Brasil, seja identificando a população em idade escolar não atendida pela escola, seja evidenciando o rendimento escolar desigual daqueles já absorvidos pela rede pública de ensino, seja evidenciando a dualidade da escola brasileira, efetivamente consolidada para uns e ainda não realizada para a maioria da população deste país.

Ampliada, diversificada e desigual, ou dual, conforme terminologia da época, a escola pública tornara-se objeto de investigação, modificando-se então a natureza das explicações sobre a desigualdade educacional. Os diagnósticos evidenciaram que a exclusão incide preponderantemente sobre as crianças das camadas mais pobres da sociedade e, assim, as explicações sobre a 'crise do ensino' abriram espaço para explicações mais ampliadas sobre a desigualdade educativa e a dualidade da escola.

$\mathrm{O}$ proceder teórico metodológico dos pesquisadores do INEP, que realizaram aqueles diagnósticos, transitou entre um projeto educacional utópico e a crítica acirrada à organização e ao funcionamento da escola.

Assim, na década de 1950, os levantamentos estatísticos já realizados - Censo de 1920, de 1940 e levantamentos estatísticos anuais, realizados pela Secretaria de Estatística da Educação e Saúde, a partir de 1932 - revelaram o déficit de vagas escolares, a dualidade do sistema de ensino e, sobretudo, os altos índices de reprovação, repetência e evasão na escola pública. Ao mesmo tempo, a escola tornara-se expressão máxima da igualdade de oportunidades, sendo vista como a via de mais fácil acesso para a mobilidade social, por ela demandando a crescente população urbana que acompanhava o avanço da economia industrial e era por ela sucumbida.

\section{Referências}

BRANDAO, Z. Diálogo com Anísio Teixeira sobre a escola brasileira. Revista Brasileira de Estudos Pedagógicos, Brasília, v. 80, n. 194, p. 95-101, 1999

- A construção de um objeto de pesquisa histórica: a escola nova no Brasil. Inter$\overline{a c ̧ a ̃ o ~(G o i a ̂ n i a), ~ v . ~ 18, ~ n .1 / 2, ~ p . ~ 27-46, ~} 1995$.

CUNHA, M. V.; T. Análise Retórica da Pedagogia do Estado Novo. Revista Educação e Cultura Contemporânea, v. 8, p. $\mathrm{n}^{\circ} 16,2011$. 
. Ciência e educação na década de 1950: uma reflexão com a metáfora percurso.

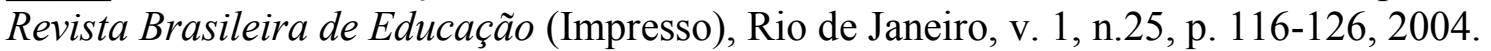

- Três versões do pragmatismo deweyano no Brasil dos anos 50. Educação e Pesquisa (USP), São Paulo, n.2, p. 39-55, 1999.

- A Dupla Natureza da Escola Nova: Psicologia e Ciências Sociais. Cadernos de Pesquisa (Fundação Carlos Chagas), SÃO PAULO, n.88, p. 64-71, 1994.

FORQUIN, Jean Claude. Escola e Cultura: as bases epistemológicas do conhecimento escolar. Porto Alegre: Artes Médicas, 1993.

FREITAS, M. A. Teixeira de. A evasão escolar no ensino brasileiro. Revista Brasileira de Estudos Pedagógicos, n..4, out. /dez. 1940.

GANDINNI, Raquel P. C. Intelectuais, Estado e Educação. Revista Brasileira de Estudos Pedagógicos - 1944-1952. Campinas: Unicamp, 1995.

GOUVEIA, Aparecida Joly. A pesquisa educacional no Brasil. Cadernos de pesquisa. São Paulo, n.1, jul. 1971.

. Orientações teórico-metodológicas da Sociologia da Educação no Brasil. Cadernos de Pesquisa. São Paulo, n. 55, p.63-67, nov. 1985.

INEP. Editorial. Revista Brasileira de Estudos Pedagógicos, n..4, p.2, out/dez, 1944.

INEP. Serviço de Estatística e Saúde. In: Revista Brasileira de Estudos Pedagógicos, vol.2, n.4, p.96, 1944.

INEP. Relatório Estudos e Pesquisas Educacionais no Ministério da Educação e Cultura. Educação e Ciências Sociais, vol. 1, n.1, p.12-13, 1956.

LEPENIES, Wlf. Ontribuition à une histoire des rapports entre la sociologie et la fhilosophie. In: Actes de la Rcherche. Paris, n.47/48, p. 37-38, jun. 1984.

LOURENÇO FILHO. M. B. Redução da taxa de analfabetismo no Brasil. Revista Brasileira de Estudos Pedagógicos, n. 100, p.249-271, out./dez. 1965.

MENDONÇA, A. W. P. C. As Políticas do INEP/MEC no contexto brasileiro dos anos 1950/1960. Educação on-line, Rio de Janeiro, n.1, p. 1-18, 2005.

- Do Pensamento Pedagógico Brasileiro à História das Ideias e Instituições Educacionais. Educação em Revista (UFMG), Belo Horizonte - MG, v. 34, n.34, p. 127 134, 2001.

O educador: De intelectual a burocrata. Educação e Sociedade, Campinas - São Paulo - Brasil, n.58, p. 156-172, 1997.

MENDONÇA, A. W. P.; XAVIER, L. N. ; BREGLIA, V. ; CHAVES, M. . Pragmatismo e desenvolvimentismo no pensamento educacional brasileiro (1950-60). Revista Brasileira de Educação, v. 11, p. 96-113, 2006. https://doi.org/10.1590/S1413-24782006000100008

MICELI, Sérgio. Intelectuais e classe dirigente no Brasil (1920-1945). São Paulo: DIFEL, 1979. 
NAGLE, Jorge. Educação e sociedade na Primeira República. São Paulo: EPU, Rio de Janeiro: Fundação Nacional do Material escolar, 1974.

NOGUEIRA, Maria Alice. A Sociologia da Educação no final dos anos 60/início dos anos 70: o nascimento do paradigma da reprodução. Em Aberto. Brasília, n. 46, p.49-58, abr./jun. 1990.

PEITAT, André. Produção da escola, produção da sociedade: análise sócio-histórica de alguns momentos decisivos da evolução escolar no ocidente. Porto Alegre: Artes Médicas, 1994.

RENAULT, Abgar. A crise do ensino. Revista Brasileira de Estudos Pedagógicos, n. 50, p.319, abr.jun. 1953.

Schwartzman, Simon et alii. Tempos de Capanema. Rio de Janeiro: Paz e Terra, São Paulo: Edusp, 1984.

TEIXEIRA, Anísio. Discurso de Posse no Instituto Nacional de Estudos Pedagógicos. Revista Brasileira de Estudos Pedagógicos, n.46, abr./jun. 1952

. A crise educacional brasileira. Revista Brasileira de Estudos Pedagógicos, n. 50, p.20-

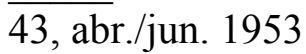
. Educação não é privilégio. Rio de Janeiro: José Olímpio, 1957.

. Educação e mundo moderno. São Paulo: Cia. Ed. Nacional, 1956.

VIDAL, Diane G. 80 anos do manifesto dos pioneiros da Educação Nova: questões para o debate. Educação e pesquisa, vol. 39, n. 3, São Paulo, jul/set. ,2013.

VIEIRA, Carlos Eduardo Intelligentsia e intelectuais sentidos, conceitos e possibilidades para a história intelectual. Revista Brasileira de História da Educação, v.16, jan./abr. 2008.

WARDE, M. J. Americanismo e educação: um ensaio no espelho. São Paulo em Perspectiva (Impresso), São Paulo, v. 14, n.2, p. 37-47, 2000.

XAVIER, M. C. (Org.). Manifesto dos Pioneiros da Educação: um legado educacional em debate. Rio de Janeiro: FGV, 2004.

XAVIER, L. N.; Mendonça, Ana Waleska. O INEP e a modernização do Ensino. Revista Contemporânea de Educação, Rio de Janeiro, v. 1, n.1, p. 1-14, 2006. 